\title{
Modelling of polypropylene fibre-matrix composites using finite element analysis
}

\author{
S. Houshyar, R. A. Shanks*, A. Hodzic \\ Applied Sciences, RMIT University, GPO Box 2476V, Melbourne, 3001, Australia
}

Received 1 September 2008; accepted in revised form 13 November 2008

\begin{abstract}
Polypropylene (PP) fibre-matrix composites previously prepared and studied experimentally were modelled using finite element analysis (FEA) in this work. FEA confirmed that fibre content and composition controlled stress distribution in all-PP composites. The stress concentration at the fibre-matrix interface became greater with less fibre content. Variations in fibre composition were more significant in higher stress regions of the composites. When fibre modulus increased, the stress concentration at the fibres decreased and the shear stress at the fibre-matrix interface became more intense. The ratio between matrix modulus and fibre modulus was important, as was the interfacial stress in reducing premature interfacial failure and increasing mechanical properties. The model demonstrated that with low fibre concentration, there were insufficient fibres to distribute the applied stress. Under these conditions the matrix yielded when the applied stress reached the matrix yield stress, resulting in increased fibre axial stress. When the fibre content was high, there was matrix depletion and stress transfer was inefficient. The predictions of the FEA model were consistent with experimental and published data.
\end{abstract}

Keywords: polymer composites, poly(propylene), finite element analysis, mechanical properties, modelling

\section{Introduction}

Polymer composites consist of two chemically distinct and physically separable constituents and they are widely used in many major engineering applications. Dispersed phase or reinforcement consists of fibres where the most common are glass, carbon, aramid, cellulose and metal oxide whiskers, used to improve the structural characteristics of the matrixphase. The matrix serves two very important functions: it bonds the fibrous phase, and under an applied force, it deforms and distributes the stress to the high-modulus fibrous constituent. The ultimate properties of composites depend on the distinct properties of the constituents, shape and size of the individual reinforcing fibres or particles, their structural arrangement and distribution, the

${ }^{*}$ Corresponding author, e-mail: Robert.shanks@ @mit.edu.au (c) BME-PT and GTE relative amount of each constituent, and the interface between reinforcement and matrix.

Thermoplastic-fibre composites of flexible polymers, such as polypropylene (PP), with natural cellulose fibres or polypropylene fibres provide environmentally friendly materials for application in construction and automotive industries $[1,2]$. The melting temperature difference between PP fibre and random poly(propylene-co-ethylene) (PPE) have been exploited to prepare an all-PP composite [3-5]. The matrix must be liquid to ensure good wetting and impregnation of fibres during formation, though temperatures must be low enough to avoid melting and degradation of fibres. The high chemical compatibility of the two components allowed creation of strong physico-chemical interactions, favouring strong interfacial adhesion 
[6, 7]. PP composites are of increasing importance because they increase the utility of PP from commodity polymer to engineering polymer applications. All-PP composites offer a new approach since they are thermoformable and recyclable as a mixture of PP grades. They avoid the abrasion to processing equipment that may occur with PP-glass fibre and other mineral filled composites. All-PP composites have been commercialized as $\mathrm{PURE}^{\circledR}$, a technology from Lankhorst Indutech bv of the Netherlands [8], Milliken and Company, Spartanburg, S.C., introduced Moldable Fabric Technology (MFT), and Curv, produced commercially in Gronau, Germany, by Amoco Fabrics and Fibers Co., a unit of BP Amoco. All-PP composites require a difference between the matrix-PP and the PP fibres that will allow the matrix to consolidate by fusion without changing the fibres, this difference maybe a PP copolymer or even differing orientation [9]. All-PP composites combine by a process analogous to welding [10] and eliminate typical interfacial weakness problems or need for compatabilisers when non-polar PP is used with inorganic fillers $[11,12]$. PP grafted with maleic anhydride is often used as a compatabiliser [13] though additional modification of fillers may be used [14]. PP fibres have lower modulus than glass fibres but can provide suitable reinforcement for many applications, and they do not suffer from exposure to variable humidity as do natural fibres such as flax [15]. Composite microstructures are determined by the physical and mechanical properties of the individual materials. Some analytical and numerical techniques have been used for prediction and characterization of composite behaviour. Analytical methods provide reasonable prediction for relatively simple configurations of the phases. Complicated geometries, loading conditions and material properties often do not yield analytical solutions, due to complexity and the number of equations. In this case, numerical methods are used for approximate solutions, but they still make some simplifying assumptions about the inherent microstructures of heterogeneous multiphase materials, one such method is finite element analysis (FEA) [8, 9]. The finite element method is an alternative approach to solving the prevailing equations of a structural problem. In the FEA method the equations are formulated for each finite element and combined to obtain a solution for the whole body instead of solving a uniform mathematical problem for the entire body. This method involves modelling the structure, using interconnected elements called finite elements, consisting of interconnected nodes and/or boundary lines and/or surfaces that are directly or indirectly linked with other elements via interfaces $[16,17]$. Each finite element has an assumed displacement field. FEA requires selection of appropriate elements of suitable size and distribution (the FEA mesh). A displacement function and material property are associated with each finite element. Boundary conditions and loading define behaviour of each node and these are expressed in matrix notations $[18,19]$.

FEA combines a model in the form of microstructures with fundamental material properties such as elastic modulus or coefficient of thermal expansion of the constitutive phases as a basis for understanding material behaviour. Solutions are stress and strain data for each node in the system and they are summarized according to the usual criteria [16-19]. The aim of this analysis was prediction of the level of stress and stress distribution in fibre, matrix and fibre-matrix interface in composite with polypropylene fibres in a poly(propylene-co-ethylene) matrix. The experimental mechanical properties of the composites were determined by the fibre composition and interfacial bonding. For composites made with a constant mass fraction of fibre but smaller fibre diameter, more fibres are necessarily present, thus increasing the total amount of interface in the material for stress transfer (the principle mechanism for achieving a stiffened composite with the same mean fibre length but smaller fibre diameter). This acts to increase the total inter-fibre interaction, reducing the fibre stress concentration about the fibre ends, thus suppressing the onset of de-bonding/shear yielding. However, for the composite with very small fibre diameter, the number of the fibres was very high and resulted in a reduction of the composite stiffness, as shown in Figure 1a. At low fibre concentration, enough fibres did not restrain the matrix and localized strains occurred in the matrix at low stresses, as shown in Figure 1b. As the fibre concentration increased to $50 \% \mathrm{w} / \mathrm{w}$, the stress was more evenly distributed and the composite stiffness increased. The deviation at high fibre concentration may be due to the (i) fibre packing, fibre-fibre contact which results in fibre damage and (ii) insufficiently rich polymer regions. 


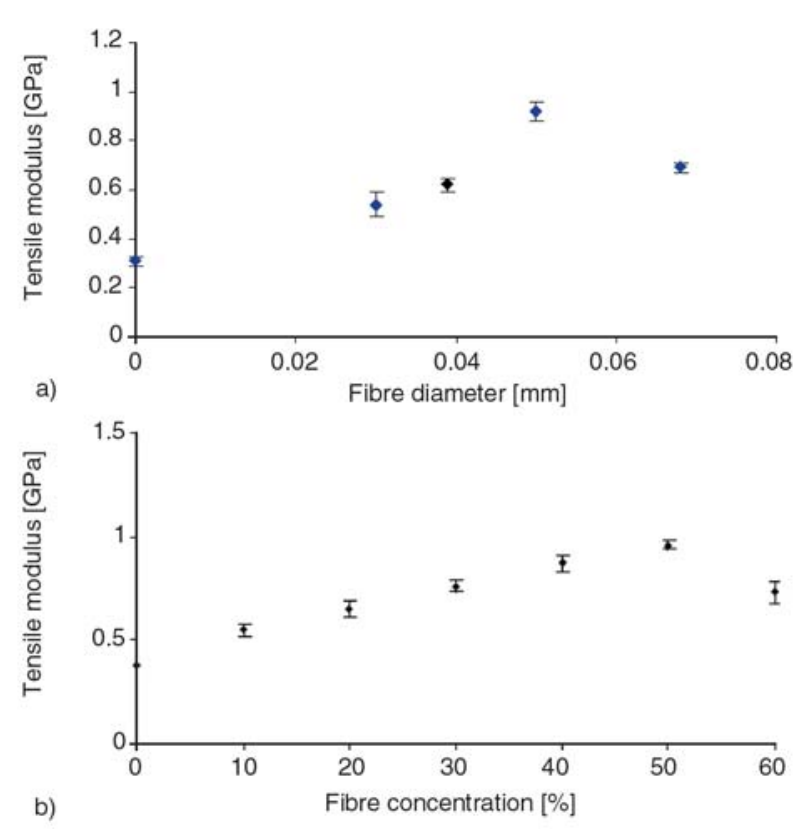

Figure 1. Tensile modulus for the composites of polypropylene fibre matrix as a function of (a) fibre diameter and (b) fibre concentration

This led to FEA investigation of the influence of fibre composition on the level of stress and stress distribution along the fibre-matrix interface, and within the fibre and matrix phases. A second objective dealt with variation of fibre content with constant material properties. The effect of fibre content on tensile properties and stress distribution in the composite are investigated in 3-dimensional (3D) mode. A third objective was to compare the all-PP composites with glass-PP and PE-PP fibre composites where the interface consists of unlike materials.

\section{The composite model}

The FEA method is used to model the behaviour of a material on the micro-mechanical level. Typically, a small section of a plate is considered, such as a square in plan view, where the side lengths are equal to the plate thickness and a complete depth of lay-up. This section is then modelled in detail using volume elements to represent the composite. Each element will have an isotropic property and be positioned corresponding to the centre line of the fibres. The model is small so a fine mesh of elements was used. This model could be used for various purposes but one factor that was important in this work, was to load it as if it were in a mechanical test instrument. All through-thickness edges could be held fixed and then boundary displacements applied to give unit strains to the model.

\subsection{FEA modelling}

A regular three-dimensional arrangement of long fibre in a matrix was adequate to describe the overall behaviour of the composite. The composite containing aligned long fibres was modelled as a regular uniform arrangement, as shown in Figure 2. This model assumed that the fibre was a perfect cylinder of length $l$, and diameter $(d=50 \mu \mathrm{m})$ in a cube of matrix. NE-Nastran FEA software version 8 and FEMAP graphics software version 7 was used for FEA in tensile mode. The model is treated as a linear axial-symmetric problem.

The FEA model in Figures 2a, 2b constituted 54600 and 104500 noded brick elements, used for a single fibre and a multiple fibre-matrix structure, respectively. The model included the fibre, the matrix and the fibre-matrix interface. Nine fibres in the matrix, Figure $2 b$, were modelled to eliminate the effect of edges on the level of stress and stress distribution in the central fibre and the surrounding matrix. The central fibre, surrounding matrix and interface were selected for stress analysis in this model. These regions were modelled using the fine mesh shown in Figure 3. Unit strain boundary conditions were applied as an imposed displacement on all boundary nodes to obtain the equivalent inplane stiffness properties. Such models give detailed stress distributions around and within the fibre once the actual strains have been determined. Equivalent properties were used in a global model, the problem was solved and the strains at any point were computed. The size of model was determined using Equation (1) [16, 17]:
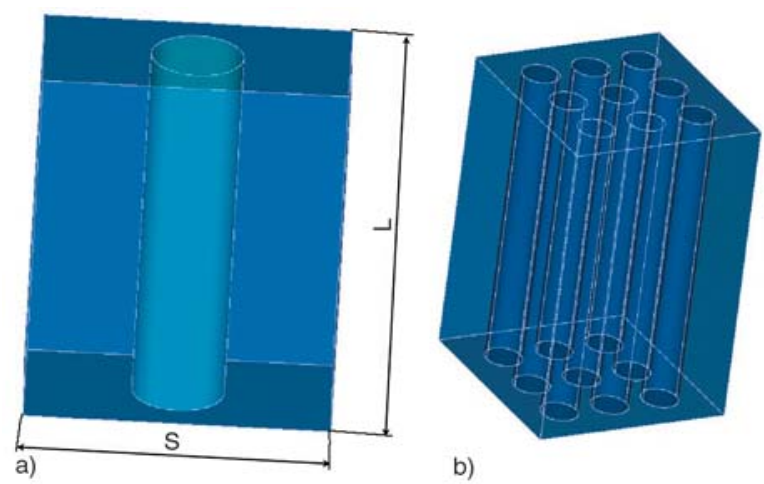

b)

Figure 2. Unit cell of square array fibre packing geometry in 3D (a) for one-fibre and (b) multiple fibres 


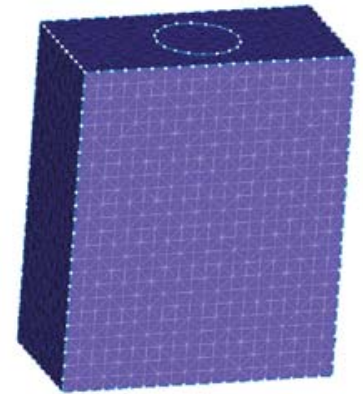

a)

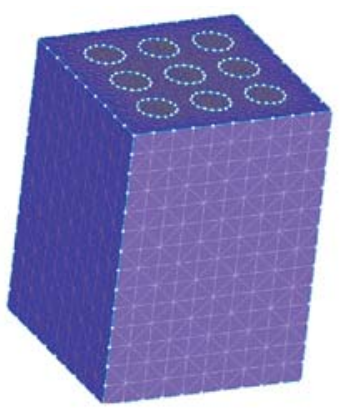

b)
Figure 3. The FEA mesh used in the present analysis shown in $3 \mathrm{D}$

$V_{f}=\frac{\pi l d^{2}}{4 L S^{2}}$

where $V_{f}$ is fibre content, $d$ is fibre diameter, $l$ is fibre length, $L$ is longitudinal fibre spacing and $S$ is fibre spacing, as shown in Figure 2.

According to the theory of effective performance, when the mean tensile strain of the model was calculated under uniform tensile stress loading (along the $z$ axis), the stress-strain behaviour of the composite could be modelled by FEA. With different micro-structural parameters considered in FEA, the correlation between tensile properties of the composite and its micro-structural parameters is discussed in this work. In this calculation, the fibre was taken as an elastic material with elastic modulus, $E_{f}=4.5$, 75, 0.3 GPa for PP, glass and polyethylene $(\mathrm{PE})$ fibre respectively and Poisson ratio of $v_{f}=0.2$. The matrix was a bi-linear material that obeyed the von Mises yielding criterion with Poisson ratio of $v_{m}=0.33$ and a tensile modulus of $1.05 \mathrm{GPa}$. No attempt was made to include a failure criterion or the effect of differential thermal deformation of the fibre and the matrix, as it was not necessary for the elastic model.

The 3D model could be subjected to loading in any direction to determine the corresponding properties and the stress-strain curve of the composite. The boundary conditions for the model include fixing one end of the model in all its three degrees of freedom and applying an axial load to the free end. The average composite stress and strain are given by Equations (2) and (3) [16, 17]:

$\bar{\sigma}=\frac{1}{V} \sum_{n=1}^{k} V_{n} \sigma_{i j}$
$\bar{\varepsilon}=\frac{1}{V} \sum_{n=1}^{k} V_{n} \varepsilon_{i j}$

where $k$ is the total number of elements, $\sigma_{i j}$ is the nth element stress, $\varepsilon_{i j}$ is the $n^{\text {th }}$ element strain and $V$ is the total volume of composite. The contribution of each element of the composite model was taken into consideration according to Equations (2) and (3). This resulted in better estimates for the elastic moduli of various composites, than the estimates of other models, such as the rule of mixture $[20,21]$ and the Halpin-Tsai [22] (H-T) equation.

\subsection{Variation of fibre composition}

Mechanical properties used in these simulations were glass, PP and PE fibres with PPE matrix properties, since these materials were used in our experimental work and other published data. In this case, the same PPE matrix was considered for all composites to investigate the effect of the reinforcement on the mechanical properties of the composite. Finally, the FEA results were compared with experimental and published data [22].

\subsection{Variation of fibre content}

Mechanical properties used in these simulations were that of PP fibre and PPE matrix, the same materials used in our experiments, to show the effect of the fibre content on the mechanical properties of the composite. Reinforcement content affects the level of stress and stress distribution in fibre, matrix and fibre-matrix interphase. In this model, fibre content was varying from 20 to $50 \% \mathrm{v} / \mathrm{v}$.

\subsection{Numerical method}

Two different composite systems have been considered in the present investigation. For the prediction of tensile properties of the two systems: (I) the same PP matrix and fibre content and, (II) the same $\mathrm{PP}$ reinforcement and matrix have been considered. This was to ensure better comparison with some published data and our experimental data as well as to show the effect of the properties of constituents on the composite properties. A comparative method has been performed [23]. 


\section{Results and discussion}

\subsection{Stress distribution}

Figure 4 illustrates the normal stress distribution for an all-PP composite. As can be seen the region surrounding the fibre and interphase exhibit complicated stress distribution. Figure 5 shows the level of stress in the fibre as well as in the fibrematrix interface. There are two important zones of stress concentration, as shown in Figure 5: (1) fibre (especially fibre skin) (2) fibre-matrix interphase.

The most important stress is at the interface. The von Mises stress shows high stress concentration in the fibre and interphase region. Figures 4 and 5 show that both the fibre and the interface in all-PP composites have uniform stress distribution. Figure 4 shows that there is a small difference between the concentrated stresses in fibre and surrounding

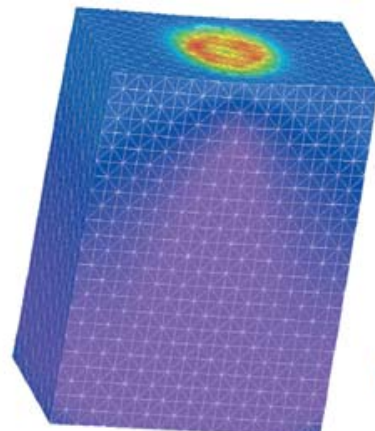

a)

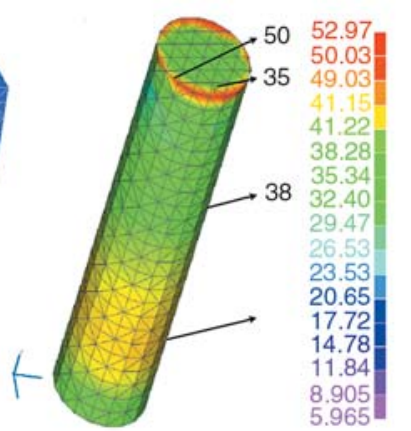

b)
Figure 4. Stress distribution in (a) composite and (b) fibre matrix. Alternatively, glass-PP and PE-PP composites exhibit a level of concentrated stress that was not uniform in both constituents and the difference between the stress in the fibre and the surrounding matrix was very high. This can result in interfacial failure at low stress.

\subsection{Variation of fibre content}

Stress distribution for the composites with varying fibres content is shown in Figures 6 and 7. In Figure 6 , the stress is plotted along the interface region, whereas Figure 7 shows stress as a function of the distance from the fibre centre to matrix. Although variation in fibre content had little effect on the stress at interphase, the difference in stress at the fibre and matrix was striking. If the fibres were packed too close, this would lead to stress concentrations and eventually de-bonding of the fibres. This means that there are detrimental effects in synergy arising from minimal matrix regions and high stress concentrations between adjacent fibres. Due to this, the composite with fibre content more than $50 \% \mathrm{v} / \mathrm{v}$ was not considered for modelling.

Figure 8 shows the stress distribution in fibres and surrounding matrix for composites with different fibre content. A rise in fibre content resulted in a more uniform stress distribution between fibre and surrounding matrix. Thus, whole fibres carried the main proportion of applied stress. However, for the

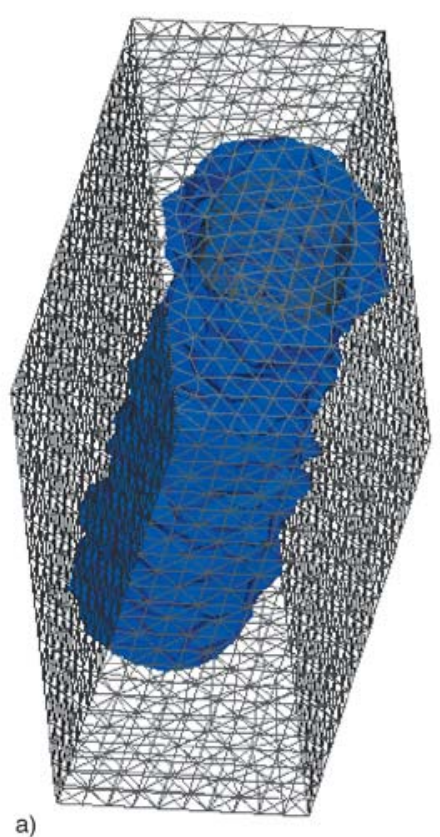

a)

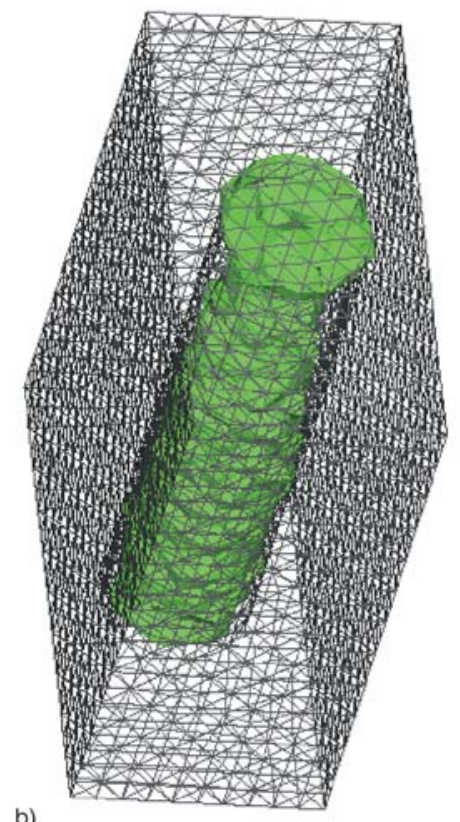

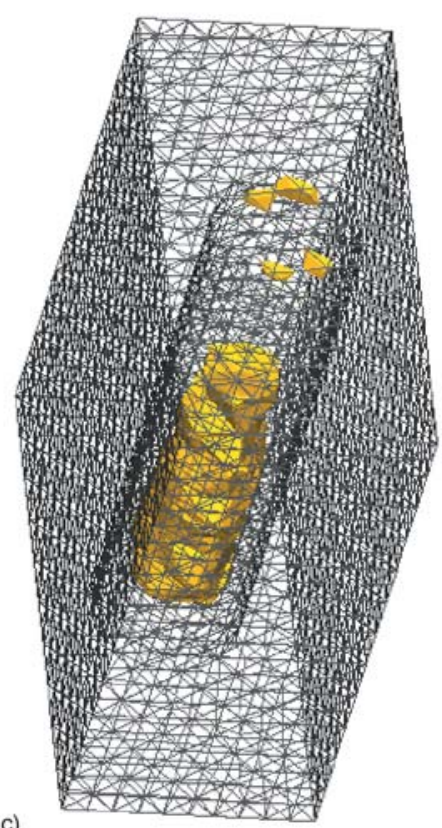

\begin{tabular}{l}
44.54 \\
41.88 \\
39.23 \\
36.57 \\
33.91 \\
31.26 \\
28.60 \\
25.94 \\
23.28 \\
20.63 \\
17.97 \\
15.31 \\
12.66 \\
9.999 \\
7.341 \\
\hline 4.683 \\
2.026
\end{tabular}

Figure 5. Details of the band illustration of normal stress at two high stress regions (a) interface and (b, c) fibre 

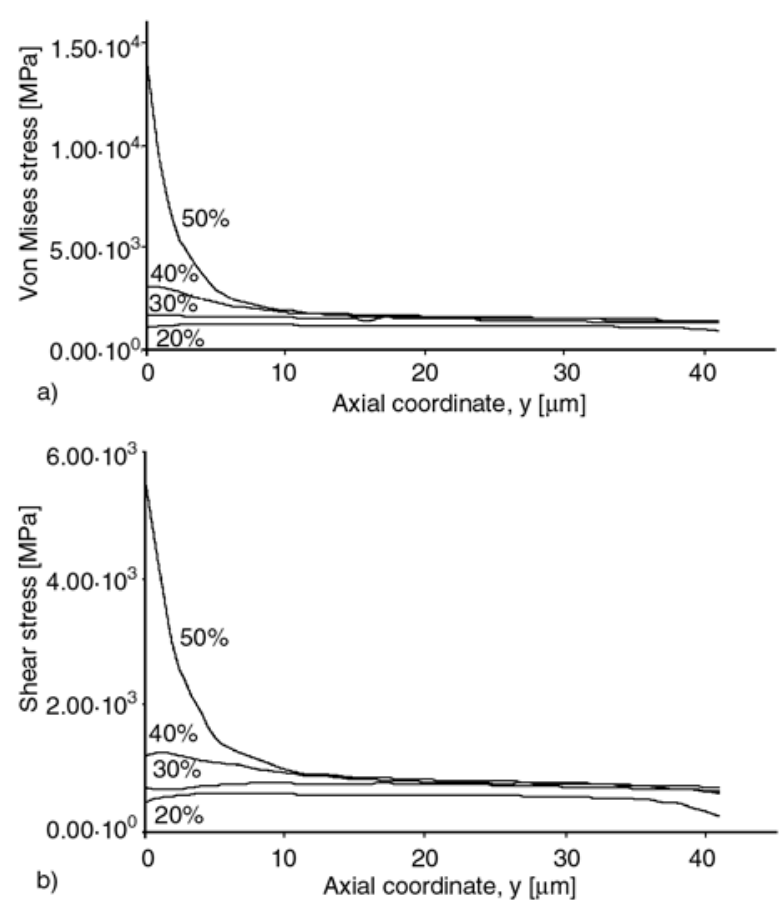

Figure 6. Distribution of axial stress in the composite with various fibre contents along the interface (a) von Mises stress and (b) shear stress
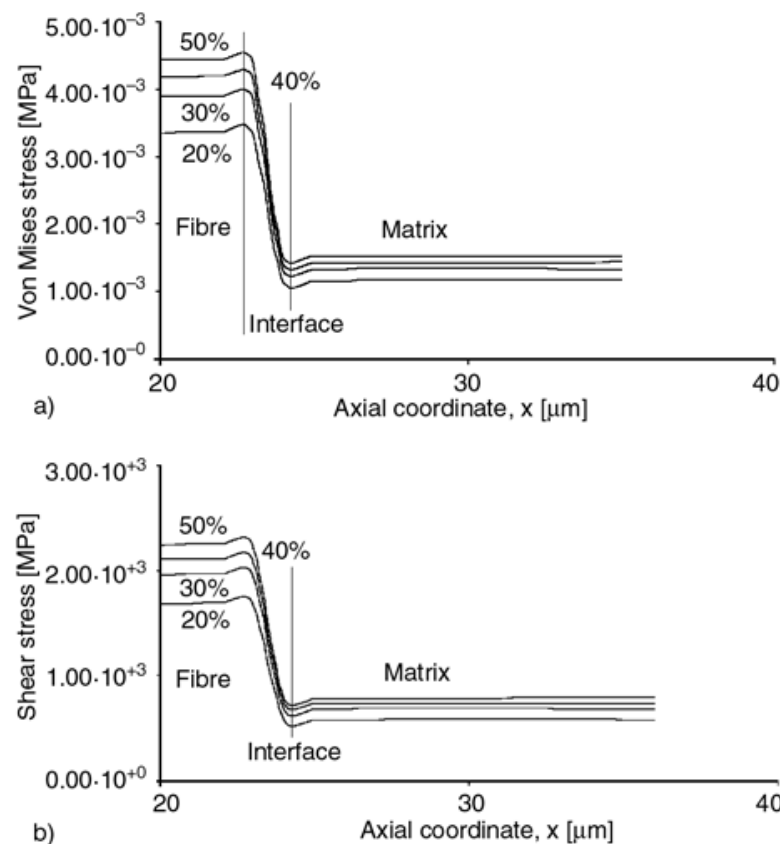

Figure 7. Distribution of axial stress in the composite with various fibre contents across the interface from $1 \mathrm{~cm}$ from the fibre end (a) von Mises stress and (b) shear stress

composite with low fibre content the matrix carried the main proportion of the applied load and tailed when the applied stress reached the matrix yield strength. The large scale yielding of the matrix resulted in increased fibre axial stress $[8,9]$. This was consistent with the experimental results. In Figure 8, the load for the two composites is the same, but the level of stress in the fibres is lower and in the matrix is higher than in the composite with lower fibre content. This means the load applied to the composite will be carried by the fibre, compared with when there is a lower fibre content present. A higher shear stress appeared at the interface for the composite with low fibre content that lead to facile interfacial failure. The fibre content of the composite was an important factor controlling the mechanical properties of the composites.

There was a deviation at high fibre content more than a critical value (50\%), because if the matrix was not adequately covering the fibres, efficient stress transfer from the matrix to the fibres was not obtained, causing a weakening effect rather than a reinforcing one in the presence of the fibres, and resulting in failure of the matrix. It is possible to reduce the stress concentration in the matrix and at the fibre-matrix interface by increasing fibre content to an optimum content. After this optimum level, the stress concentration increased at the fibrematrix interface and in the matrix resulting in composite failure at lower stress, as predicted by FEA. The simplest model for the micromechanics of fibre composites is that of Cox $[20,21]$ that is used in an analysis known as classical shear lag, where the theory required that simplifications are made. The assumptions are:

1. The interface between the two components is perfect;

2. The fibre and matrix remain elastic in their mechanical responses;

3. No axial load is transmitted through the fibre ends.

This gave the following equation, a simple rule of mixtures (Equation (4)):

$E_{c}=V_{f} \cdot E_{f}+V_{m} \cdot E_{m}$

where $E$ is tensile modulus, $V$ is volume fraction, and $c, f$ and $m$ represent composite, fibre and matrix, respectively. Following these assumptions a certain length of fibre is required for the transfer of shear stress from the matrix surrounding embedded fibres in a fibre composite under load.

Another model was introduced by Halpin, Tsai and Kardos, based on [22], which is an empirical 


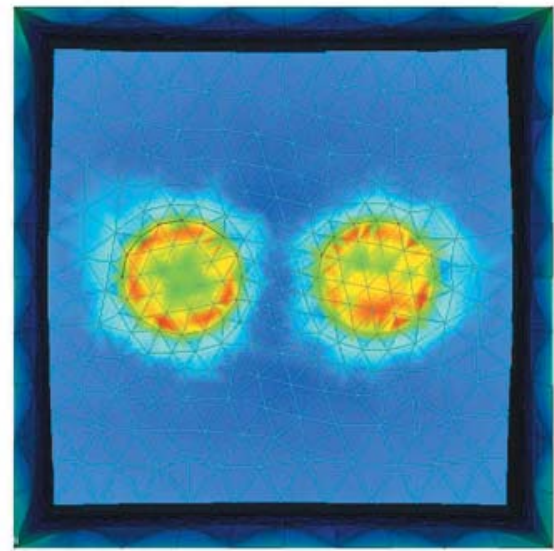

a)

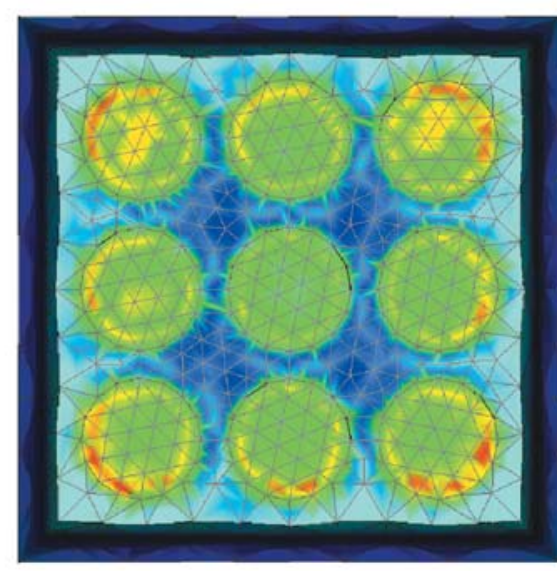

b)

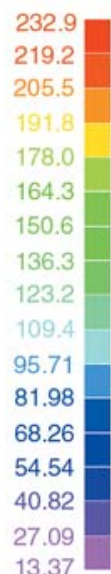

13.37

Figure 8. FEA representation of the normal stress distribution in the cross section of the composite with (a) 20 and (b) $50 \%$ wt fibre content

expression containing a geometric fitting parameter $A$, obtained by fitting with the numerical solution of formal elasticity theory. Composite moduli are put in the form (Equations (5) and (6)):

$E_{c}=\frac{E_{m}(1+A B \Phi)}{1-B \Phi}$

where

$$
B=\frac{\frac{E_{f}}{E_{m}}-1}{\frac{E_{f}}{E_{m}}+A}
$$

$A=2(l / d)$ for tensile modulus. The ratio $l / d$ is the aspect ratio. These equations are accurate for low fibre volume fractions. They are useful in determining the properties of composites that contain discontinuous fibres oriented in the loading directions

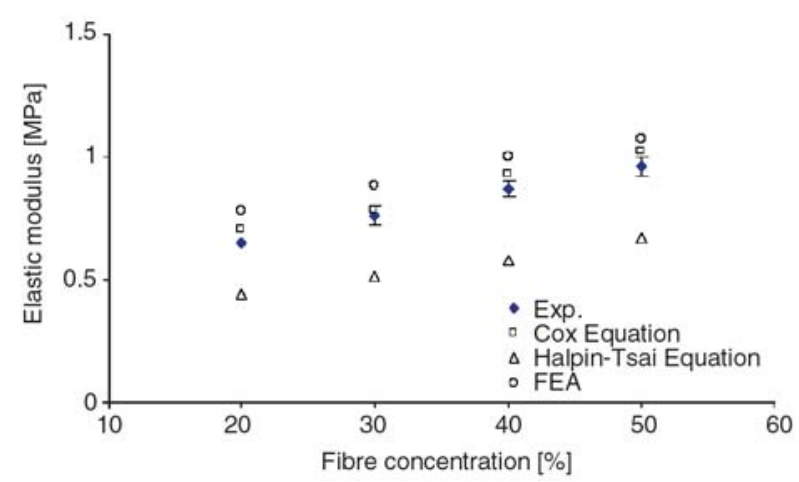

Figure 9. Comparison of the present FEA, rule of mixtures (Cox) equation, experimental data and the $\mathrm{H}-\mathrm{T}$ equation predictions of Young's modulus of all-PP composites
Figure 9 shows the elastic modulus of the PP composite with different fibre concentrations and predictions of the H-T, rule of mixtures (Cox), FEA and the experimental data. As can be seen from this figure the results of both the present FEA and Cox equations agree well. However the results from the $\mathrm{H}-\mathrm{T}$ were found to be lower than those predicted by FEA and Cox equations. Cox equation fit the data better because the experimental and model systems approximate to the three assumptions, while the $\mathrm{H}-\mathrm{T}$ equation is not satisfied in that there is not a low fibre volume content and the fibres where not discontinuous in each system studied.

\subsection{Variation of fibre composition}

The von Mises and shear stress of the two important regions in the FEA model were analysed: (a) along the interfacial region, defined as the bonding line between the fibre and matrix; (b) along the specimen surface, where high stress was initiated by the applied force. Variation in fibre composition showed significant influence on the stress region in the composite, and on the resulting mechanical properties of the composite. The stresses in the interface regions in the three systems are shown in Figure 10.

When the fibre stiffness was too high or too low in comparison with the matrix, the load shared by the fibres significantly declined. There was a large difference between the level of stress in the fibres and matrix and high shear stress at the interface of the glass-PP composite leading to a high chance of interfacial de-bonding or failure at low stress. High 


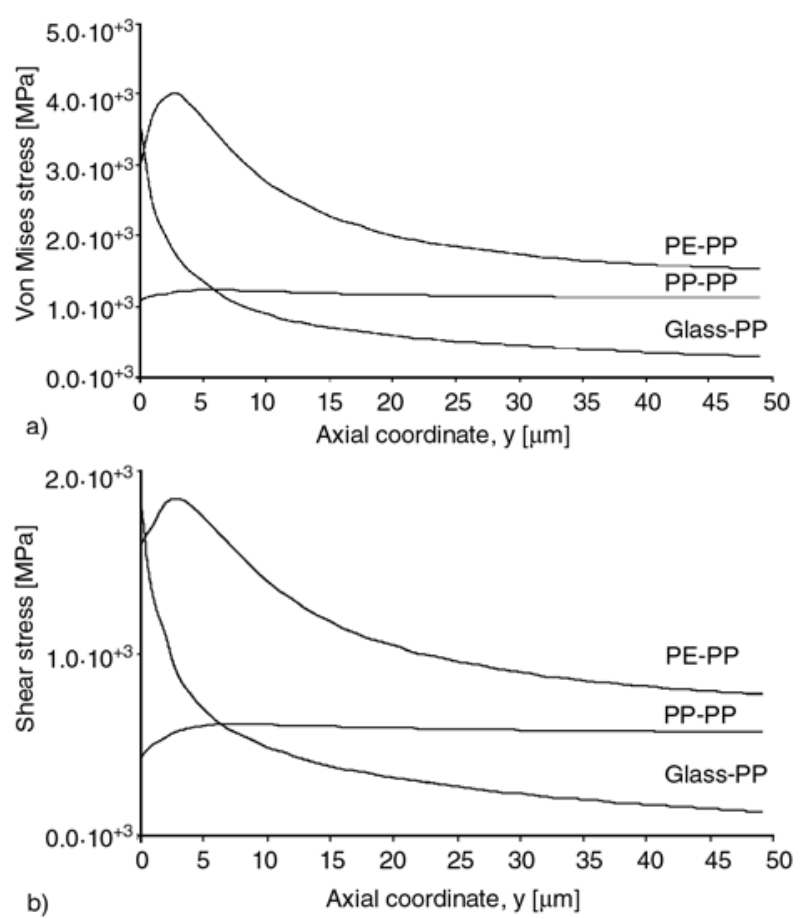

Figure 10. Distribution of axial stress in the composite with various fibre compositions along the interface (a) von Mises stress and (b) shear stress

fibre strength and stiffness are not an advantage, whereas in all-PP composites, the level of stress in fibre and matrix were close, leading to uniform stress distributions along the fibre-matrix interface and uniform performance of the composite. In this case, an applied load was transferred from the matrix to the fibre and the fibres retained a high proportion of the applied load in the composite during the test. According to the results for the PEcomposites, the load did not transmit to the fibre from the matrix. PE fibre carried lower load than the matrix, which led to composite failure at low applied load. Figure 10 shows that the shear stress at the interface of this type of composite was more than that in the fibre and matrix. This increased the risk of premature interfacial failure and reduced the mechanical properties of the composite.

Figure 11 shows the von Mises and shear stress along the specimen surface. The figure supports the results from Figure 10 and shows an uneven stress distribution and a great difference between the level of stress in the surrounding matrix and the fibre in a glass-PP and PE-PP system in comparison with the all-PP system, leading to stress concentration in the interfacial region. This results in an easy separation of fibre from the matrix when a high load was applied. In this case, the shear stress
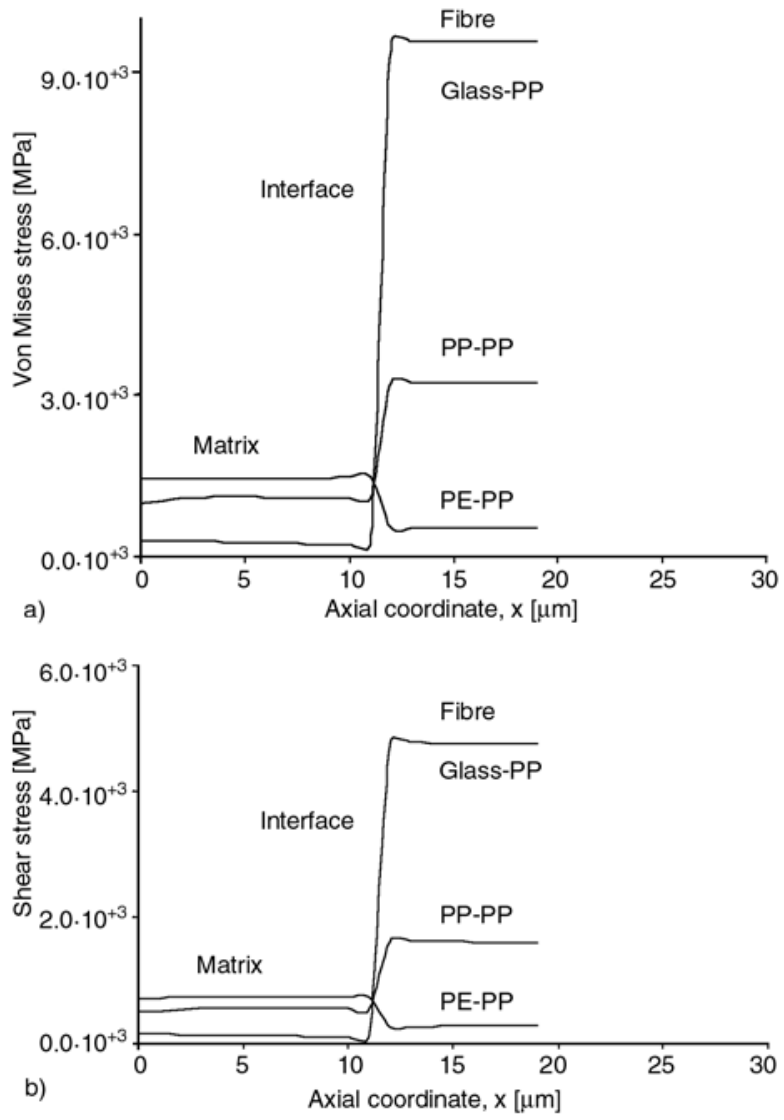

Figure 11. Distribution of axial stress in the composite with various fibre compositions across the interface (a) von Mises stress and (b) shear stress

at the interface was more than the normal stress. This means that interfacial shear de-bonding may occur under a critical applied stress, instead of the interfacial normal de-bonding. However, in the case of an all-PP system, the interfacial shear stress became lower than interfacial normal de-bonding. Thus, interfacial normal de-bonding, instead of interfacial shear de-bonding may occur when a critical applied stress was reached.

In glass-PP system the level of high stress on the interphase and the fibre cannot contribute to transmitting the load in the composite and the strength and stiffness of the fibre was not important. However, in PE-PP systems, the stress was high in the matrix and again the fibre could not reinforce the composite, due to the low stiffness and strength.

Figure 12 shows the 3D model of a glass-PP composite under an applied load. It can be seen from this figure that the stress concentrated at the fibre is 20 times more than the stress in the surrounding matrix. In this case $\left(E_{\text {matrix }} / E_{\text {fibre }}\right)$ was too small, so a high shear stress appeared at the interface and 


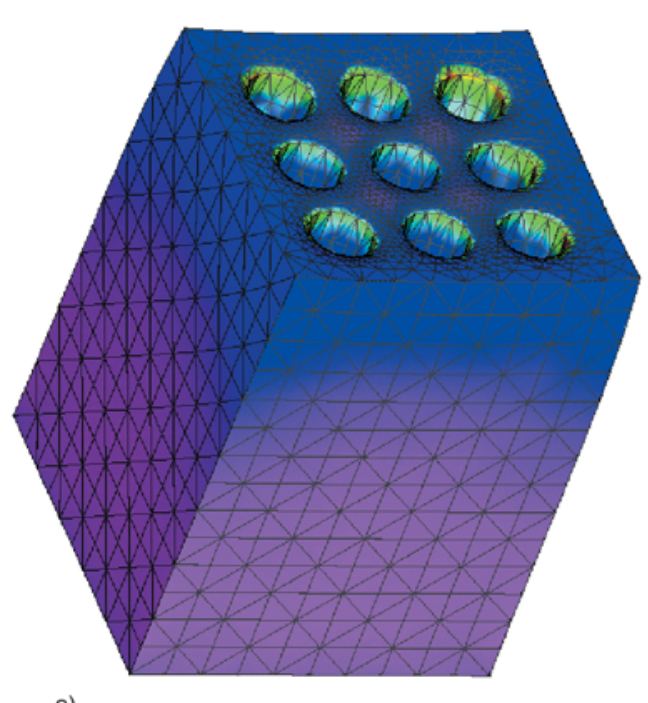

a)

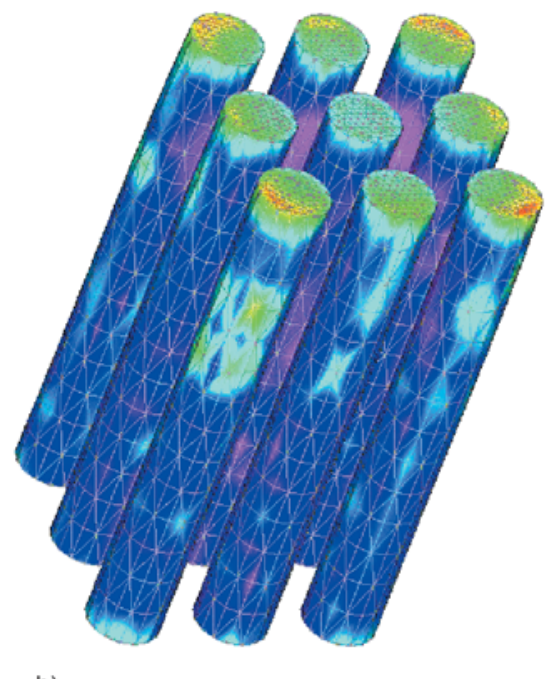

b)
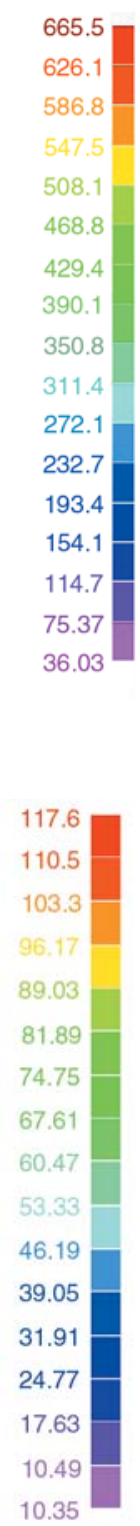

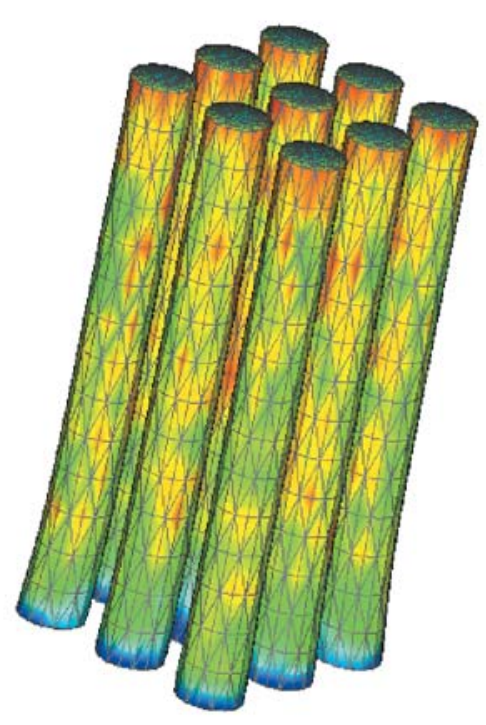

Figure 13. Stress distribution in (a) PE-PP composite and (b) PE fibre in the composite

interfacial shear failure would easily occur. Thus, this could be a weak point in mechanical properties of this system.

Figure 13 shows the 3D model for a PE-PP composite. The stress distribution and concentration are shown. In this composite the PE fibre has a lower stiffness than the matrix. The PE fibres cannot share a large portion of the applied stress and the matrix carried the main portion of the applied load. For example, the fibre took about $25 \%$ of the load carried by the surrounding matrix.

As observed from Figure 14, the stress distribution in an all-PP system is uniform in the fibres and surrounding matrix. In all-PP systems, fibre and matrix possess similar stiffness, and a significant portion of the applied load was transferred to the fibre. Thus, the stress concentration at the fibrematrix interface was not too high, and posed no risk of premature interfacial failure. In this case, the fibres act as reinforcement for the lower stiffness matrix and improved the mechanical properties of the matrix. The results showed the advantages of using the same fibre and matrix in a composite.

\section{Conclusions}

It was shown using FEA, that the fibre content and composition had a dominant influence on stress distribution in polypropylene composites. The stress concentration at the fibre-matrix interface 


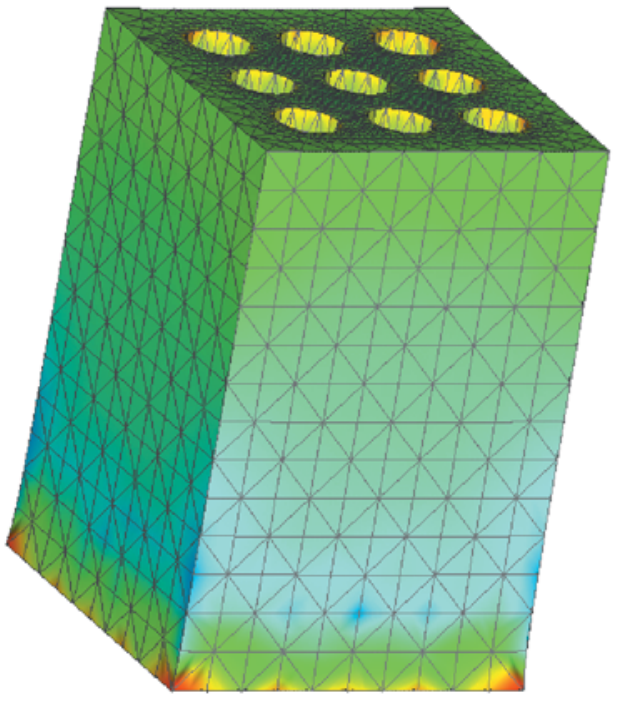

a)

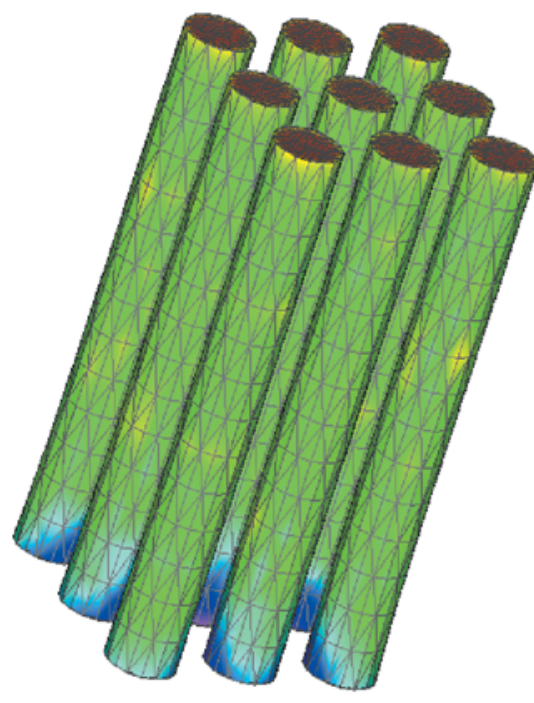

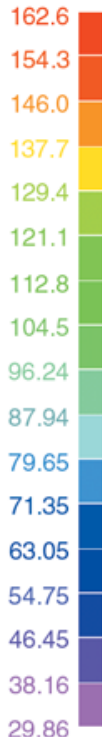

29.86

Figure 14. Stress distribution in (a) all-PP composite and (b) PP fibre in the composite

increased with decrease in fibre content. The variations in fibre composition influenced the higher stress region of the composites. As the fibre stiffness increased, the load shared by the fibres significantly declined and the shear stress at the fibrematrix interface increased. As was observed for the all-PP system, the ratio between matrix and fibre stiffness was significant and the interfacial stress carried by both constituents acted to reduce the risk of premature interfacial failure and increased the mechanical properties of the composite. FEA results for this part of the investigation were consistent with prior experimental data.

The FEA model showed that with low fibre content, the fibre was not able to share a large portion of applied stress. The matrix carried the main portion of the applied stress and yielded over a large scale when the applied stress reached the matrix strength, resulting in increased fibre axial stress that was predicted by FEA. In the case of high fibre content, there was insufficient matrix to cover the fibre and stress transfer was inefficient. The predictions of the FEA model were consistent with experimental and published data.

\section{Acknowledgements}

Financial support from International Postgraduate Scholarship (IPRS) for Shadi Houshyar is acknowledged.

\section{References}

[1] Shanks R. A.: Alternative solutions: Recyclable synthetic fibre-thermoplastic composites. in 'Green Composites: Polymer Composites and the Environment' (ed.: Baillie C.) Woodhead Publishing, Cambridge 100-122 (2004).

[2] Wong S., Shanks R. A., Hodzic A.: Poly(L-lactic acid) composites with flax fibres modified by plasticizer absorption. Polymer Engineering and Science, 43, 1566-1575 (2003). DOI: $10.1002 /$ pen.10132

[3] Houshyar S., Shanks R. A., Hodzic A.: The effect of fibre concentration on mechanical and thermal properties of fibre reinforced polypropylene composites. Journal of Applied Polymer Science, 96, 2260-2272 (2005).

DOI: 10.1002/app.20874

[4] Houshyar S., Shanks R. A., Hodzic A.: Tensile creep behaviour of polypropylene fibre reinforced polypropylene composites. Polymer Testing, 24, 257-264 (2005).

DOI: $10.1016 /$ j.polymertesting.2004.07.003

[5] Houshyar S., Shanks R. A., Hodzic A.: Influence of different woven geometry in poly(propylene) woven composites. Macromolecular Materials and Engineering, 290, 45-52 (2005). DOI: $\underline{10.1002 / \mathrm{mame} .200400158}$

[6] Houshyar S., Shanks R. A.: Tensile properties and creep response of polypropylene fibre composites with variation of fibre diameter. Polymer International, 53, 1752-1759 (2004).

DOI: $\underline{10.1002 / \text { pi.1569 }}$ 
[7] Houshyar S., Shanks R. A.: Morphology, thermal and mechanical properties of poly(propylene) fibre-matrix composites. Macromolecular Materials and Engineering, 288, 599-606 (2003).

DOI: $10.1002 /$ mame.200300023

[8] Abraham T., Banik K., Karger-Kocsis J.: All-PP composites $\left(\mathrm{PURE}^{\circledR}\right)$ with unidirectional and cross-ply lay-ups: Dynamic mechanical thermal analysis. Express Polymer Letters, 1, 519-526 (2007). DOI: 10.3144/expresspolymlett.2007.74

[9] Izer A., Bárány T.: Hot consolidated all-PP composites from textile fabrics composed of isotactic PP filaments with different degrees of orientation. Express Polymer Letters, 1, 790-796 (2007). DOI: $10.3144 /$ expresspolymlett.2007.109

[10] Varga J., Ehrenstein G. W., Schlarb A. K.: Vibration welding of alpha and beta isotactic polypropylenes: Mechanical properties and structure. Express Polymer Letters, 2, 148-156 (2008). DOI: $10.3144 /$ expresspolymlett.2008.20

[11] Cai L. F., Mai Y. L., Rong M. Z., Ruan W. H., Zhang M. Q.: Interfacial effects in nano-silica/polypropylene composites fabricated by in-situ chemical blowing. Express Polymer Letters, 1, 2-7 (2007). DOI: 10.3144/expresspolymlett.2007.2

[12] Turmanova S. Ch., Genieva S. D., Dimitrova1 A. S., Vlaev L.T.: Non-isothermal degradation kinetics of filled with rise husk ash polypropene composites. Express Polymer Letters, 2, 133-146 (2008). DOI: $10.3144 /$ expresspolymlett.2008.18

[13] Prashantha K., Soulestin J., Lacrampe M. F., Claes M., Dupin G., Krawczak P.: Multi-walled carbon nanotube filled polypropylene nanocomposites based on masterbatch route: Improvement of dispersion and mechanical properties through PP-g-MA addition. Express Polymer Letters, 2, 735-745 (2008). DOI: 10.3144/expresspolymlett.2008.87

[14] Pannirselvam M., Genovese A., Jollands M. C., Bhattacharya S. N., Shanks R. A.: Oxygen barrier property of polypropylene-polyether treated clay nanocomposite. Express Polymer Letters, 2, 429-439 (2008). DOI: $10.3144 /$ expresspolymlett.2008.52
[15] Bledzki A. K., Mamun A. A., Lucka-Gabor M., Gutowski V. S: The effects of acetylation on properties of flax fibre and its polypropylene composites. Express Polymer Letters, 2, 413-422 (2008).

DOI: $10.3144 /$ expresspolymlett.2008.50

[16] Shati F. K., Esat I. I., Bahai H.: FEA modelling of visco-plastic behaviour of metal matrix composites. Finite Elements in Analysis and Design, 37, 263-272 (2001).

DOI: $10.1016 / \mathrm{S} 0168-874 \mathrm{X}(00) 00042-1$

[17] Kang G. Z., Gao Q.: Tensile properties of randomly oriented short $\delta-\mathrm{Al}_{2} \mathrm{O}_{3}$ fibre reinforced aluminium alloy composites: II. Finite element analysis for stress transfer, elastic modulus and stress-strain curve. Composites Part A, Applied Science and Manufacturing, 33, 657-667 (2002). DOI: $10.1016 / \mathrm{S} 1359-835 \mathrm{X}(02) 00006-4$

[18] Hodzic A., Stachurski Z. H.: Droplet on a fibre: Surface tension and geometry. Composites and Interfaces, 8, 415-425 (2001). DOI: $\underline{10.1163 / 156855401753424451}$

[19] Huang A., Bush M. B.: Finite element analysis of mechanical properties in discontinuously reinforced metal matrix composites with ultra fine micro structure. Materials Science and Engineering, A, 232, 63 72 (1997).

DOI: 10.1016/S0921-5093(97)00092-0

[20] Krenchel H.: Fibre reinforcement. Akademisk Forlag, Copenhagen (1964).

[21] He T., Porter R. S.: Melt transcrystallization of polyethylene on high modulus polyethylene fibres. Journal of Applied Polymer Science, 35, 1945-1953 (1988). DOI: 10.1002/app.1988.070350720

[22] Ibarra L., Macias M., Palma E.: Viscoelastic properties of short carbon fibre thermoplastic (SBS) elastomer composites. Journal of Applied Polymer Science, 57, 831-842 (1995). DOI: 10.1002/app.1995.070570707

[23] Maligno A. R., Warrior N. A., Long A. C.: Finite element investigations on the microstructure of fibrereinforced composites. Express Polymer Letters, 2, 665-676 (2008). DOI: $10.3144 /$ expresspolymlett.2008.79 